\title{
Vectoelectronystagmography in children with dyslexia and learning disorder
}

\author{
Ana Carla Leite Romero(1) \\ Mariana Banzato Stenico(2) \\ Letícia Sampaio de Oliveira(2) \\ Eloisa Sartori Franco(3) \\ Simone Aparecida Capellini(2) \\ Ana Claudia Figueiredo Frizzo(2)
}

(1) Faculdade de Medicina da Universidade de São Paulo, Campus Ribeirão Preto, São Paulo, Brasil.

(2) Faculdade de Filosofia e Ciências - FFC, UNESP, Marília, São Paulo, Brasil.

(3) Universidade Estadual de Campinas UNICAMP, Campinas, São Paulo, Brasil.

Conflict of interests: Nonexistent

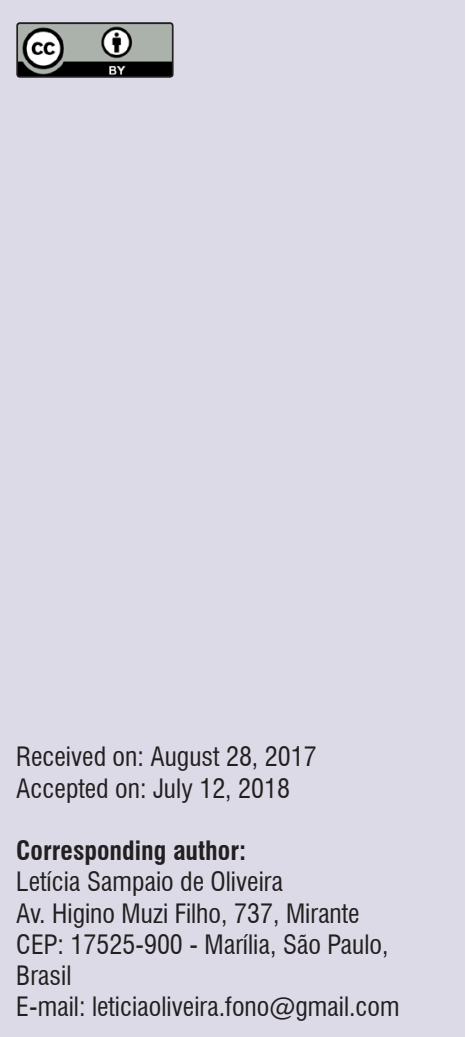

\section{ABSTRACT}

Objective: to describe and compare the results of ocular (saccadic, screening, and optokinetic) tests of vectoelectronystagmography among the groups with dyslexia, learning disorder and control.

Methods: 28 male and female students aged 8 to 11 years participated in this study. They were divided into three groups: Group I, 10 students with dyslexia, Group II, 9 students with learning disorders and Group III, 9 students with no learning disorders. In this research, digital vectoelectronystagmography - ocular test - was performed.

Results: saccadic movement, optokinetic nystagmus, and pendular tracking tests were found to show subtle differences among the three groups. Comparing the saccadic eye movements and the optokinetic nystagmus tests, it was observed that the movement in the left eye was slower for Group I, and even slower for Group II. It was also observed that Gl and Gll were slower for the pendular tracking of luminous stimulus in relation to the control group.

Conclusion: in general, there are differences among the groups in the vectoelectronystagmography, which indicated slower tracking and vestibulo-ocular reflex in children with dyslexia and learning disorders.

Keywords: Vestibular Diseases; Dyslexia; Learning Disorder 


\section{INTRODUCTION}

Digital vectoelectronystagmography is one of the most used methods reported in the literature to evaluate vestibular function, the exam has greater diagnostic sensitivity as it allows to measure the parameters of the vestibulo-oculomotor function through the comparison between the stimuli and the responses, in addition to identifying the direction of ocular phenomena ${ }^{1-3}$.

The Diagnostic and Statistical Manual of Mental Disorders (DSM-V) aims to help in the diagnosis of mental and neurodevelopment disorders by describing the most common characteristics and symptoms of a particular disease. According to the DSM-V, a learning disorder consists of a wide range of specific disorders of hearing, speech, reading, writing and mathematics, and is most prevalent among the diagnoses of learning disabilities ${ }^{4,5}$.

Dyslexia is a developmental disorder characterized by significant and specific difficulties in reading and writing, such as difficulties in acquiring basic skills such as reading words and spelling and decoding skills, resulting in phonological deficit, changes in lexical development, and executive functions, in addition to low performance in tasks of sustained visual attention ${ }^{6-8}$.

According to the literature ${ }^{9}$, two factors seem to explain learning disorders: inability with coordination movements and absence of perception of their spatial position. Most of the children are not able to practice physical exercises, have abnormal head positions during writing, distort the size and weight of their own body and objects around them.

The literature ${ }^{10,11}$ reports the relation between dyslexia and learning disorders with fine motor coordination changes, as well as the relation between perceptual-motor changes and the reading performance of these children. The literature highlights the importance of understanding these relationships at the time of evaluation and diagnosis.

In clinical practice, children with visual and auditory attention difficulties are often observed; and as they need to follow the teacher in their visual field in the classroom, they need to make copies, to read the book's tasks, and to concentrate, their oculomotor functions and vestibular interconnections need to be sound $^{12}$.

The saccadic pathway involves several regions of the cerebral cortex, cerebellum, and brain stem. The parameters latency, velocity and accuracy of saccadic movements evaluate the efficiency of central nervous system (CNS) control over rapid eye movements ${ }^{13}$.
Thus, such information may be extremely important for the evaluation and intervention of children with dyslexia.

Authors ${ }^{14}$ claim that early identification of vestibular disorders in children and initiation of their treatment is essential to prevent and solve school complications, which often occur.

Therefore, this study aims to describe and compare the results of ocular tests (saccadic movement, pendular tracking, and optokinetic nystagmus) among the groups with dyslexia, learning disorders and control group.

\section{METHODS}

The study was carried out after the approval by the Ethics Committee in Research of Faculdade de Filosofia e Ciências, UNESP, under number: 0694/2013. All subjects were invited to participate in the study and signed the Informed Consent.

A total of 28 schoolchildren of both genders, aged 8 to 11 years, attending the $3^{\text {rd }}$ to $5^{\text {th }}$ year of municipal public schools in a city in the state of São Paulo, were divided into three groups.

Group I (GI): Composed of 10 students, four female and six male schoolchildren, with the interdisciplinary diagnosis of Dyslexia, according to the DSM-V ${ }^{4}$ criteria, enrolled in a municipal school in a city in the State of São Paulo and in a waiting list for care service in the Rehabilitation Specialized Center.

Group II (GII): Composed of nine students, four female and five male schoolchildren, with an interdisciplinary diagnosis of Learning Disorder, according to DSM V4 criteria, enrolled in a municipal school in a city in the State of São Paulo, in a waiting list for care service in the Rehabilitation Specialized Center.

Group III (GIII): Composed of nine students without learning difficulties from a municipal public school in a city in the state of São Paulo, matched according to gender and age with groups I and II.

Participants from groups I and II were diagnosed at school and had a persistent documented history of school impairment. All participants had mean performance on WISC-II intelligence tests (80 was chosen as the cutoff point). Reading and writing tests were carried out to measure reading speed and spelling to characterize the groups, as well as spelling and phonological awareness tests.

The students in GIll were referred by the school teachers based on the information contained in the school records and the performance report of the students in the first two bimesters of the academic 
year, and those who presented satisfactory performance in two consecutive bimesters in Portuguese language tests were considered as students with good academic performance; those who presented unsatisfactory performance in two consecutive bimesters in Portuguese Language tests were discarded from this study.

None of the participants had previous history of neurological diseases, psychiatric disorders or hearing problems. In addition, participants with comorbidities regarding attention and/or behavior issues were excluded from the study.

All children included in the study underwent previous screening procedures: (1) Inspection of the auditory canal; (2) Tonal threshold audiometry; (3) Logoaudiometry; (4) Acoustic immitance measurements.

For the present study, the following procedures were used:

Firstly, regular calibration and absence of spontaneous and semi spontaneous nystagmus with open and closed eyes were observed, to exclude the presence of primary vestibular pathology.

Next, an evaluation of the digital vectoelectronystagmography was performed with the equipment Neurograff - Eletromedicina Ind. \& Com. Ltda. Surface electrodes were attached with adhesive tape together with a paste for conducting the electrical signal in the periorbital region of the subject, after cleaning the skin with abrasive substance (gauze soaked in alcohol), as described in the literature ${ }^{9}$, to form a $30^{\circ}$ isosceles triangle.

Electrodes 1 and 2 were placed in the outer corner of the right eye and the left eye, respectively, and electrode 3 was placed on the forehead to form the apex of the triangle. The ground electrode was fixed in the frontal region to ease possible interference in the recording. All data collection was performed individually in a 60-minute session in the Institution's Auditory Objective Assessment Laboratory (Laboratório de Avaliação Objetiva da Audição da Instituição).

Previous guideline to the exam: Selected subjects were instructed to avoid foods containing caffeine and non-essential drugs for 72 hours prior to the test. The test was performed with a four-hour fasting.

Calibration of eye movements: The children were instructed to stand with their heads upright and still, sitting on the chair, and looking alternately at the light points that appeared on the bar placed in the horizontal plane in front of them, in order to make a deviation of $10 \circ$ to the right and to the left, for 20 seconds at $0.30 \mathrm{~Hz}$, according to the parameters suggested in the Neurograff version 3.0 user manual. Previous training was carried out with the subjects and the vectoelectronystagmography measurement was started when the ideal - reference tracing configuration was reached.

Saccadic movement tests: The children were instructed to follow the light point on the bar, which ignited randomly for 20 seconds at $0.70 \mathrm{~Hz}$, evaluating the integrity of the CNS for rapid movements.

Pendular tracking tests: The children were instructed to follow the light point in the horizontal plane, which glided along the bar forming a sinusoidal curve at the frequencies of $0.10 \mathrm{~Hz} 0,20 \mathrm{~Hz}$ and $0,40 \mathrm{~Hz}$.

Optokinetic nystagmus tests: The children were instructed to count the points that appeared in the horizontal plane for 30 seconds at $1.00 \mathrm{~Hz}$ clockwise and counterclockwise, thus producing a nystagmus by the visual follow-up of the light points that moved from one side to the other.

\section{Statistical analysis}

Descriptive analyzes of the test results were performed, from the construction of tables with mean values and standard deviation, by group, ear and eye. Shapiro-Wilk test was applied to verify data normality.

The comparison of the numerical variables between the studied groups was carried out through the analysis of variance - F-Test (ANOVA), parametric test to compare means using the variance in data which necessarily configure normal distribution.

The result was described as $p$ value, and the level of significance was always $5 \%$ or 0.05 ( $p \leq 0.05)$. The statistics software was SPSS ${ }^{\circledR} 9.0$.

\section{RESULTS}

Table 1 shows the mean values, standard deviation and comparison ( $p$ value) between dyslexia and control groups from ocular evidence of saccadic eye movements and optokinetic nystagmus test of the right eye.

When comparing GI and GIII for the saccadic eye movement tests and optokinetic nystagmus analysis, no statistically significant differences were observed (Table 1). 
Table 1. Mean, Standard Deviation and comparison ( $p$ value) between dyslexia and control groups of ocular tests of saccadic eye movements and optokinetic nystagmus of the right eye

\begin{tabular}{|c|c|c|c|c|}
\hline Variable & & Mean & SD & P Value \\
\hline \multicolumn{5}{|c|}{ Sac. Mov. RE } \\
\hline \multirow[t]{2}{*}{ Lat } & $\mathrm{Gl}$ & 163.81 & 47.95 & \multirow{2}{*}{0.78} \\
\hline & GIII & 169.65 & 43.07 & \\
\hline \multirow[t]{2}{*}{ Vel } & $\mathrm{Gl}$ & 91.36 & 12.83 & \multirow[b]{2}{*}{0.32} \\
\hline & GIII & 104.16 & 36.88 & \\
\hline \multirow[t]{2}{*}{ Accuracy } & $\mathrm{Gl}$ & 104.71 & 32.10 & \multirow{2}{*}{0.64} \\
\hline & GIIII & 111.23 & 28.01 & \\
\hline \multicolumn{5}{|l|}{ Optok. RE } \\
\hline \multirow{2}{*}{ S-VEL } & $\mathrm{Gl}$ & 11.60 & 3.30 & \multirow{2}{*}{0.62} \\
\hline & GIII & 10.60 & 2.12 & \\
\hline \multirow[t]{2}{*}{ Gain } & $\mathrm{Gl}$ & 0.93 & 0.28 & \multirow{2}{*}{0.93} \\
\hline & GIII & 0.92 & 0.19 & \\
\hline \multirow[t]{2}{*}{$\mathrm{DP}$} & $\mathrm{Gl}$ & 5.86 & 4.90 & \multirow{2}{*}{0.98} \\
\hline & GIII & 6.12 & 4.15 & \\
\hline
\end{tabular}

Caption: SD = standard deviation; Sac. Mov. = saccadic movement; RE = right eye; Lat = latency; Vel = velocity; S-VEL = slow-phase velocity of nystagmus; $\mathrm{DP}=$ directional preponderance.

(F-Test ANOVA - significance level $p \leq 0.05$.)

In the comparison of Gll and GIll for the results of saccadic eye movement tests and optokinetic nystagmus tests, there was also no significant difference (Table 2).
There was no significant difference between Gl and GIII in the comparison of saccadic eye movements and optokinetic nystagmus tests, except for the slower movement velocity of the left eye in the group with dyslexia (Table 3).

Table 2. Mean, Standard Deviation and comparison ( $p$ value) between the learning disorder and control groups of ocular tests of saccadic eye movements and optokinetic nystagmus of the right eye

\begin{tabular}{|c|c|c|c|c|}
\hline Variable & & Mean & SD & $P$ Value \\
\hline \multicolumn{5}{|c|}{ Sac. Mov. RE } \\
\hline \multirow[t]{2}{*}{ Lat } & Gll & 157.72 & 36.51 & \multirow{2}{*}{0.53} \\
\hline & GIII & 169.65 & 43.07 & \\
\hline \multirow[t]{2}{*}{ Vel } & Gll & 84.84 & 38.75 & \multirow{2}{*}{0.29} \\
\hline & GIII & 104.16 & 36.88 & \\
\hline \multirow[t]{2}{*}{ Accuracy } & Gll & 86.58 & 33.53 & \multirow{2}{*}{0.11} \\
\hline & GIII & 111.23 & 28.01 & \\
\hline \multicolumn{5}{|l|}{ Optok. RE } \\
\hline \multirow[t]{2}{*}{ S-VEL } & Gll & 10.04 & 3.31 & \multirow{2}{*}{0.91} \\
\hline & GIII & 10.60 & 2.12 & \\
\hline \multirow[t]{2}{*}{ Gain } & Gll & 0.79 & 0.27 & \multirow{2}{*}{0.52} \\
\hline & GIII & 0.92 & 0.19 & \\
\hline \multirow[t]{2}{*}{ DP } & Gll & 4.84 & 0.27 & \multirow{2}{*}{0.78} \\
\hline & GIII & 6.12 & 4.15 & \\
\hline
\end{tabular}

Caption: SD = standard deviation; Sac. Mov. = saccadic movement; RE = right eye; Lat = latency; Vel = velocity; S-VEL = slow-phase velocity of nystagmus; DP = directional preponderance.

(F-Test ANOVA - significance level $p \leq 0.05$.) 
Table 3. Mean, Standard Deviation and comparison ( $p$ value) between the dyslexia and control groups of ocular tests of saccadic eye movements and optokinetic nystagmus of the left ey

\begin{tabular}{|c|c|c|c|c|}
\hline Variable & & Mean & SD & P Value \\
\hline \multicolumn{5}{|c|}{ Sac. Mov. LE } \\
\hline \multirow[t]{2}{*}{ Lat } & $\mathrm{Gl}$ & 175.54 & 36.68 & \multirow{2}{*}{0.80} \\
\hline & GIII & 171.70 & 30.67 & \\
\hline \multirow[t]{2}{*}{ Vel } & $\mathrm{Gl}$ & 94.89 & 19.40 & \multirow[b]{2}{*}{0.06} \\
\hline & GIII & 118.31 & 31.10 & \\
\hline \multirow[t]{2}{*}{ Accuracy } & $\mathrm{Gl}$ & 99.97 & 17.43 & \multirow{2}{*}{0.25} \\
\hline & GIIII & 111.66 & 25.96 & \\
\hline \multicolumn{5}{|l|}{ Optok. LE } \\
\hline \multirow[t]{2}{*}{ S-VEL } & $\mathrm{Gl}$ & 10.69 & 2.90 & \multirow{2}{*}{0.92} \\
\hline & GIII & 10.53 & 3.87 & \\
\hline \multirow[t]{2}{*}{ Gain } & $\mathrm{Gl}$ & 0.90 & 0.28 & \multirow{2}{*}{0.93} \\
\hline & GIII & 0.95 & 0.27 & \\
\hline \multirow[t]{2}{*}{$\mathrm{DP}$} & $\mathrm{Gl}$ & 5.86 & 4.90 & \multirow{2}{*}{0.98} \\
\hline & GIII & 6.12 & 4.15 & \\
\hline
\end{tabular}

Caption: SD = standard deviation; Sac. Mov. = saccadic movement; LE = left eye; Lat = latency; Vel = velocity; S-VEL = slow-phase velocity of nystagmus; DP = directional preponderance.

(F-Test ANOVA - significance level $p \leq 0.05$.)

In the comparison between Gll and GIII in the saccadic eye movement tests compared to optokinetic nystagmus tests, there was no significant difference, except for the latency of the saccadic movement of the left eye, which had the longest latency in the group with learning disorder (Table 4).
In general, Gl and Gll were slower for the pendular tracking with light stimulus in relation to the control group (Table 5 and 6).

Table 4. Mean, Standard Deviation and comparison ( $\mathrm{p}$ value) between the learning disorder and control groups of ocular tests of saccadic eye movements and optokinetic nystagmus of the left eye

\begin{tabular}{|c|c|c|c|c|}
\hline Variable & & Mean & SD & P Value \\
\hline \multicolumn{5}{|c|}{ Sac. Mov. LE } \\
\hline \multirow[t]{2}{*}{ Lat } & Gll & 221.96 & 53.33 & \multirow{2}{*}{$0.02^{*}$} \\
\hline & GIII & 171.70 & 30.67 & \\
\hline \multirow[t]{2}{*}{ Vel } & Gll & 217.85 & 412.82 & \multirow{2}{*}{0.48} \\
\hline & GIII & 118.3 & 31.10 & \\
\hline \multirow[t]{2}{*}{ Accuracy } & Gll & 99.23 & 28.51 & \multirow[b]{2}{*}{0.35} \\
\hline & GIII & 111.66 & 25.96 & \\
\hline \multicolumn{5}{|l|}{ Optok. LE } \\
\hline \multirow[t]{2}{*}{ S-VEL } & Gll & 9.63 & 2.91 & \multirow{2}{*}{0.58} \\
\hline & GIIII & 10.53 & 3.87 & \\
\hline \multirow[t]{2}{*}{ Gain } & Gll & 0.76 & 0.28 & \multirow{2}{*}{0.34} \\
\hline & GIIII & 0.95 & 0.27 & \\
\hline \multirow[t]{2}{*}{$\mathrm{DP}$} & Gll & 4.85 & 2.51 & \multirow{2}{*}{0.94} \\
\hline & GIII & 6.12 & 4.15 & \\
\hline
\end{tabular}

Note: ${ }^{*} p<0.05$

F-Test ANOVA - significance level $p \leq 0.05$.

Caption: SD = standard deviation; Sac. Mov. = saccadic movement; LE = left eye; Lat = latency; Vel = velocity; S-VEL = slow-phase velocity of nystagmus; DP = directional preponderance. 
Table 5. Mean, SD and comparison ( $p$ value) between dyslexia and control groups of ocular tests of pendular tracking

\begin{tabular}{ccccc}
\hline Variable & & Mean & SD & P Value \\
\hline Pendular Tracking & GI & 1.01 & 0.28 & \\
Gain 0.10 & GIII & 1.02 & 0.70 & 0.98 \\
Gain 0.20 & GI & 1.11 & 0.28 & 0.41 \\
& GIII & 1.26 & 0.28 & \\
Gain 0.40 & GI & 0.98 & 0.28 & $0.04^{*}$ \\
& GIII & 1.30 & 0.24 & \\
\hline
\end{tabular}

Note: ${ }^{*} p>0.05$.

F-Test ANOVA - significance level $p \leq 0.05$

Caption: $\mathrm{SD}=$ standard deviation.

Table 6. Mean, SD and comparison ( $\mathrm{p}$ value) between learning disorder and control groups of ocular tests of pendular tracking

\begin{tabular}{ccccc}
\hline Variable & & Mean & SD & P Value \\
\hline Pendular Tracking & GII & & & \\
Gain 0.10 & GIII & 0.65 & 0.18 & 0.20 \\
Gain 0.20 & GII & 1.01 & 0.70 & $0.02^{*}$ \\
& GIII & 0.86 & 0.31 & \\
Gain 0.40 & GII & 1.26 & 0.28 & 0.14 \\
& GIII & 1.03 & 0.26 & 0.24 \\
\hline
\end{tabular}

Note: ${ }^{*} p>0.05$

F-Test ANOVA - significance level $p \leq 0.05$.

Caption: $\mathrm{SD}=$ standard deviation.

\section{DISCUSSION}

From the results of the present study and the literature, it is possible to conclude that otoneurological evaluation should always be indicated for patients with suspected or diagnosed with learning disorders and/ or poor school performance, as patients often present vestibular alteration with evident repercussion in their postural balance, which often causes changes in the notion of laterality and space, in addition to causing inattention in the classroom ${ }^{15}$.

The literature has reported that the spatial perception of children with vestibular disorder is worse than in children without this disorder in relation to the use of a sheet of paper when drawing and the proportion between objects. However, if the otoneurological evaluation is not performed, the poor spatial perception may be confused with other disorders, especially in the school phase when the child is asked to perform this type of activity. It is concluded, therefore, that early diagnosis of vestibulopathy is important to initiate treatment/rehabilitation; and symptoms, such as spatial disorientation, do not influence learning ${ }^{16}$ or is not confused with learning disorders and/or dyslexia.

Thus, professionals in the field should better understand the occurrence of vestibular system disorders in childhood, which can cause changes in motor development and acquisition of oral and written languages, affecting communication skills, psychological behavior and school performance ${ }^{17}$. They also cause difficulties in oral and written language as a consequence of compromising posture and body balance, as well as motor coordination, and interfere with spatial relationships and adequate contact with the environment, also changing children's learning and ability to communicate ${ }^{18}$.

It is noteworthy that other authors found that approximately $56.8 \%$ of the students with some kind of otoneurological complaint have poor school performance. On the other hand, the same unsatisfactory performance reaches $63.6 \%$ of the students who reported having no complaints $^{18}$. Further studies are needed to correlate reading and writing performance with otoneurological examination results in schoolchildren, especially 
comparing children suspected or diagnosed with a language disorder with children with typical development, to investigate the prevalence of vestibular disorders in schoolchildren with language impairment.

In this study, after vectoelectronystagmography, it was verified that the saccadic movement, optokinetic nystagmus and pendular tracking tests showed subtle differences among the groups of children with dyslexia and learning disorder in relation to the control group. For the saccadic eye movement and optokinetic nystagmus tests, there was no statistically significant difference in any group, except for the movement velocity of the left eye which was slower in both pathological groups.

These results are similar to those found in the literature in which otoneurological changes were also observed in children with developmental disorders, such as attention deficit hyperactivity disorder, dyslexia, and learning disorders ${ }^{19,20}$. Such changes may be related to a possible inefficiency of the central nervous system control on the rapid movements of the eyes, a function which is compromised in children with difficulty in reading and writing ${ }^{15}$, as the ocular movement required for reading requires alternating saccadic movements and the eye control during periods of fixation, requiring perfect integrity of the vestibular apparatus and its saccadic movements ${ }^{16,17}$.

The findings on pendular tracking, in general, indicate that the groups with dyslexia and learning disorder were slower than the control group, which, according to the literature, is related to the incomplete maturation of the pathways controlling the slowtracking ocular movements, and/or poor attention span of children in the pathological group, and may only result in slower trackings ${ }^{16,17}$.

It is believed that otoneurological evaluation can become a more efficient instrument in the evaluation and possible diagnosis in these children, and may also aid in speech-language intervention ${ }^{5,21}$, which, from the otoneurological results, can focus on activities that train notions of laterality and space, in addition to reading and writing, or even the joint activities. Therefore, it is suggested that this subject be approached in future studies, as the national literature investigating the evaluations of vectoelectronystagmography in children with dyslexia and learning disorders is scarce.

\section{CONCLUSION}

In general, significant differences were observed among the groups for the vectoelectronystagmography measurement, which indicate slower vestibular-ocular reflexes and tracking in children with dyslexia and learning disorders.

\section{REFERENCES}

1. Mor R. Fragoso M. Vestibulometria na prática fonoaudiológica. São José dos Campos, São Paulo: Pulso Editorial; 2012.

2. Caovilla HH, Ganança MM, Munhoz MSL, Silva MLG, Frazza MM. Body equilibrium and its disorders: Part V: value of computed nystagmography. Braz J Otorhinolaryngol. 1997;4(5):158.

3. Soriano-Ferrer M. Implicaciones educativas del deficit cognitivo de la dislexia evolutiva. Rev Bras Neurol. 2004;38(1):47-52.

4. American Psychiatric Association. DSM-5 Development [Internet]. 2011 [cited 2012 Aug 27]. Available from: http://www.dsm5.org/Pages/ Default.aspx.

5. Ganança MM, Caovilla HH. A múltipla abordagem terapêutica. In: Ganança MM (org). Vertigem tem cura? São Paulo: Lemos; 1998. p.59-61.

6. Lyon GR, Fletcher JM, Barnes MC. Learning disabilities. In: Mash EJ, Barkley RA (ed). Child Psychopathology: Guilford Press. 2003; 2nd edition. p.157-79.

7. Oliveira AM, Germano GD, Capellini SA. Comparação por sexo do desempenho em leitura de escolares com dislexia do desenvolvimento. Paidéia. 2017;27(68):306-13.

8. Mc Hugh HE. Auditory and vestibular disorders in children. Laryngoscope. 1962;72:555-65.

9. Silva NSM, Crenitte PAP. Linguistic, familial and gender profile of students diagnosed with dyslexia of a school clinic. Rev. CEFAC. 2014;16(2):463-71.

10. Shawitz SE. Dyslexia. N Engl j med. 1998;338(5):307-12.

11. Shaywitz BA, Shaywitz SE, Pugh KR, Mencl WE, Fullbright RK, Skudlarski $P$ et al. Disruption of posterior brain systems for reading in children with developmental dyslexia. Biol Psychiatry. 2002;52(2):101-10.

12. Mathes PG, Denton CA. The prevention and identification of reading disability. Semin pediatr neurol. 2002;9(3):185-91.

13. Ventura DFP, Ganato L, Mitre El, Mor R. Parâmetros de oculomotricidade à nistagmografia digital em crianças com e sem distúrbios de aprendizagem. Braz J Otorhinolaryngol. 2009;75(5):733-7. 
14. Mor R, Fragoso M, Taguchi CK, Figueiredo JFFR. Vestibulometria \& Fonoaudiologia - Como realizar e interpretar. São Paulo: Lovise; 2001.

15. Marchesin VC, Caovilla HH, Ganança MM. Saccadic eye movements in children with auditory processing disorders. Acta ORL. 2005;23(2):7-12.

16. Santos MTM, Behlau MS, Caovilla HH. Dyslexic children: nystagmographic evaluation of eye movement in reading. Rev Bras Med. Otorrinolaringol. 1995;2(2):100-7.

17. Franco ES, Panhoca I. Otoneurologic evaluation in children with school difficulties: vestibular function investigation. Rev Bras Otorrinolaringol. 2007;73(6):803-15.

18. Pereza MLD, Lemosb NF, Aprilea MR, BrancoBarreiro FCA. Sintomas otoneurológicos em escolares. Rev. Equilíbrio Corporal Saúde. 2014;6(2):48-53.

19. Aksoy S, Akdogan O, Gediklil Y, Belgin E. The extent and levels of tinnitus in children of central Ankara. Int J Pediatric Otorhinolaryngol. 2007;1 (2):263-8

20. Mangabeira PLA, Gananca MM, Caovilla HH, Ito YI, Casto HD. Atlas de vecto-electronistagmografia. São Paulo, Ache; 1984.

21. Novalo ES, Goffi-Gomez MVS, De Medeiros IRT, Pedalini MEB, Dos Santos RMR. A afecção vestibular infantil: estudo da orientação espacial. Rev. CEFAC. 2007;9(4):519-31. http://dx.doi. org/10.1590/S1516-18462007000400013.

\section{ERRATUM}

In the article, "Vectoelectronystagmography in children with dyslexia and learning disorder" with DOI number: $10.1590 / 1982-0216201820412717$, published in the journal Revista Cefac, 20(4):442-449, in author name:

\section{Where it was:}

Ana Carla Romero Leite

Read:

Ana Carla Leite Romero 